\title{
Literatura, Política e Pessoalidade: lógicas cruzadas de atuação no espaço intelectual maranhense (1945-1964)
}

Franklin Lopes Silva ${ }^{2}$

\section{Resumo}

Este trabalho investiga as diferentes estratégias, espaços e modalidades de atuação em que se insere um conjunto de agentes que ingressaram na carreira literária entre os anos de 1945 e 1964 no Maranhão. As variáveis constituintes de seus perfis sociais foram analisadas de forma relacional, identificando-se as dimensões e princípios de hierarquização constituintes deste espaço social, considerando-se os investimentos feitos no âmbito cultural, político e de relações sociais.

Palavras-chave: Literatura; Política; Recursos Sociais; Estratégias

\section{Literature, Politics and Personhood: cross-action logics in the intellectual spa- ce in the state of maranhão (1945-1964)}

\section{Abstract}

This paper investigates the different strategies, spaces and forms of action that fits a set of agents who have joined the literary career between the years 1945 and 1964 in Maranhao. The variable constituents of their social profiles were analyzed re-

1 Este trabalho é uma síntese de nossa monografia de graduação em Ciências Sociais na Universidade Federal do Maranhão. Agradeço imensamente a Igor Gastal Grill, orientador desta pesquisa, a Eliana Tavares dos Reis e Wheriston da Silva Neris, componentes da banca de avaliação. Contamos também com o auxílio imprescindível de uma bolsa de iniciação científica concedida pela FAPEMA. Email: franklinlopes@gmail.com

2 Mestre em História Social pela Universidade Federal do Maranhão. 
lational, identifying the dimensions and principles of social hierarchy constituents of this space, considering the investments made in the cultural, political and social relations.

Keywords: Literature; Politics; Social Resources; Strategies

\section{INTRODUÇÃO}

Detendo-nos sobre a análise das estratégias ${ }^{3}$ de afirmação social acionadas por um conjunto de 37 agentes $^{4}$ ingressantes na carreira literária no Maranhão entre os anos de 1945 a 1964, investigamos uma série de interseções e lógicas de cruzadas, atuação e consagração em domínios que, a despeito de possuírem certos limites, apresentam-se imbricados, concomitantemente inseridos e penetrados por circuitos híbridos de funcionamento, o que implica em modalidades difusas no processo de consagração destes agentes.

Quanto aos critérios metodológicos no processo de constituição das variáveis utilizadas, orientamo-nos no sentido de apreender os diferentes usos dos recursos sociais, tangíveis ou não, em posse dos agentes analisados, como estratégias de inserção e afirmação no espaço intelectual. Contudo, tratando-se de domínios pouco obstruídos por forças internas autônomas na forma de princípios próprios de legitimação e "mecanismos de censura a pautas exógenas", estes diferentes usos prescindem da "necessidade imediata de reconversão de um domínio para o outro". Portanto, semelhantemente ao cuidado empregado por Eliana

3 Para Bourdieu, a noção de estratégia não diz respeito a um cálculo sistemático, mas à relação - também não plenamente inconsciente - entre as disposições incorporadas ao longo das trajetórias dos agentes e o que está em jogo no espaço social em que se inserem, ou seja, pelo acionamento de recursos tangíveis ou intangíveis condicionados a meio caminho entre as determinações objetivas e as disposições incorporadas.

4 Segue anexa uma lista com os nomes dos agentes em questão. 
Reis na identificação dos diferentes recursos (herdados ou adquiridos) que possuíam os agentes que analisara (REIS, 2001, 2007), e tratando-se de contextos em semelhantes condições periféricas tomaremos esta circulação entre domínios pela noção de "papéis que são endossados e que solicitam dos seus protagonistas o desenvolvimento de habilidades prescritas para o trânsito entre linguagens e domínios, assim com para o uso de lógicas multidimensionais" (REIS, 2007, p. 58).

Para a construção do que tratamos por espaço intelectual e análise das estratégias de afirmação, disputas e repertórios nele acionados, constituíram-se em importantes fontes para obtenção de dados relativos aos agentes em questão, as publicações biográficas promovidas por instituições dedicadas à consagração de personagens que se destacaram no cenário "intelectual" maranhense, como a Academia Maranhense de Letras (AML) e o Instituto Histórico e Geográfico do Maranhão (IHGM). Além destes, recolhemos informações de biografias, livros de memórias, prefácios, antologias, sites particulares ou institucionais, entrevistas, materiais produzidos pelos movimentos culturais de que participaram e alguns trabalhos acadêmicos que nos auxiliaram no mapeamento e caracterização historiográfica do período em pauta e no conhecimento dos "pares geracionais", que constituem os casos em análise. Ainda a partir destes trabalhos pudemos cotejar discursos de posse, homenagens, artigos, e perceber algumas adesões ou oposições e suas ligações por parentesco, amizade ou política entre os nomes a que se vinculavam. A relevância destes dados também se manifesta pelo destaque conferido aos movimentos culturais como espaços privilegiados de afirmação "intelectual”, através das possibilidades de publicação à dispensa dos incentivos públicos dirigidos a produções desta ordem, bem como do acesso a semelhantes incentivos através de reciprocidades concedidas aos agentes pertencentes aos mesmos grupos. Além disso, o pertencimento a estes movimentos culturais lhes possibilitava o compartilhamento de sentidos, afirmados nas disputas pela afirmação entre agentes estabelecidos e 
a substituição por novos “autores”, em posse de diferentes recursos sociais na busca pelo reconhecimento dos mais reconhecidos e de poderem reivindicar-se "escritores" (BOURDIEU, 2005). Ainda quanto a este processo de hierarquização social, cumprem as instituições um importante papel no decurso da consagração e cristalização biográfica de alguns personagens ilustres. Por exercerem localmente este papel, duas destas instituições têm destacada importância no desenvolvimento deste trabalho: o IHGM e a AML. Estas trazem entre seus patronos e fundadores nomes consagrados na, e pela, historiografia maranhense, cultivados como referenciais estratégicos no processo de auto afirmação; em alguns casos construindo-se sentidos de grupo (REIS, 2007, p. 295), em torno dos quais alguns se aglutinam reivindicando-se continuadores de um legado da "tradição literária maranhense", ou tomados por outros como parâmetro de superação, caracterizando-se pela reivindicação de uma "literatura marginal" e inovadora, que busca outros "estilos", temáticas e formas de reconhecimento.

\section{Posições no espaço e produção literária}

Do ponto de vista analítico empregado neste trabalho, a análise da produção literária pressupõe a investigação do "sistema de desvios do qual ela se situa no espaço das obras contemporâneas". Esta etapa fundamental para a investigação das disposições acionadas pelos agentes em suas "obras" exige, inelutavelmente, a "apreensão estrutural do respectivo autor" que se apreende a partir das "relações objetivas que definem e determinam sua posição no espaço de produção" (BOURDIEU, 2004, p.177-178). Assim, identificamos alguns elementos que se destacam a partir do trabalho de produção ideológica de suas vidas (Cf. BOURDIEU, 2005, p. 74-89) e cruzamo-los com as características mais distintivas entre seus perfis sociais, elaborados a partir da construção de quadros sinópticos. Como resultado pretendemos a demonstração das relações existentes entre as condições sociais de ingresso na carreira literária, a posição que ocupa no espaço intelectual maranhense pelos usos de 
recursos sociais herdados ou adquiridos por novos investimentos (formação superior, experiências em outros estados ou no exterior etc.) e, a guisa de micro análises, a objetivação destas características em alguns fragmentos de publicações.

Sem perder de vista o fato de terem estes "intelectuais" ingressado na carreira literária entre os anos de 1945 e 1964, destaca-se o montante de suas primeiras publicações voltadas em sua maior parte para o gênero poético $(59,4 \%)$. Esta observação conjugada ao período de ingresso destes agentes na carreira literária adquire relevância ao percebermos as relações entre seus perfis sociais, suas consequentes posições ocupadas no jogo de relações em que se inserem e as mudanças ou permanências dos gêneros a que se dedicaram no ingresso e decorrer de suas carreiras literárias.

Quadro 01 - Gênero da primeira publicação (\%)

\begin{tabular}{|c|r|}
\hline Gênero & $\mathrm{N}^{\circ}$ de casos \\
\hline Poesia & $22(59,4)$ \\
\hline Romance & $3(8,1)$ \\
\hline Ensaio & $4(10,8)$ \\
\hline Teatro & $1(2,7)$ \\
\hline Conto & $2(5,4)$ \\
\hline Crônica & $1(2,7)$ \\
\hline Científico & $4(10,8)$ \\
\hline Total & $37(100)$ \\
\hline
\end{tabular}

Fonte: repertórios biográficos

Considerando a idade dos agentes em suas primeiras publicações literárias, os dados demonstram um número acentuado com idade até 25 anos (29,7\%), percentual aumentado em dois terços se prolongarmos este período de ingresso na carreira literária até os 30 anos (51,3\%). 0 cruzamento entre as duas va- 
riáveis apresentadas nos quadros acima - idade e gênero relativos à primeira publicação - e considerando-se também o fato de se localizarem estes agentes em posições sociais dominadas no domínio da política, serem identificados sob a mesma categoria de "escritores" e em sua maioria $(75,6 \%)$ exercerem funções administrativas no estado, em geral voltados à produção cultural, apontam para a existência entre eles de um princípio estratégico relativamente homogeneizante, com vias às modalidades de trabalho "intelectual" mais rentáveis e gratificantes, homologamente tendentes à aproximação/distanciamento com o polo mais dominante/dominado do estado, percebidas a partir dos gêneros de publicação aos quais mais se dedicaram nas entradas e transcorrer de suas carreiras literárias.

A importação de referenciais oriundos de países mais centrais insere-se também entre os importantes recursos acionados por alguns desses agentes nas disputas que travam. A exemplo disso veja-se a lista de autores enfatizada por Nauro Machado quando indagado acerca de suas principais influências literárias. Figuram entre elas: Dostoievski, Thomas Mann, Rimbaud, Mallarmé, Bocage, Baudelaire, entre outros. A importação de seus "estilos" e temáticas literárias acompanha, por analogia, a expectativa de reconhecimento que possuem e os estilos de vida construídos pelo trabalho de produção de suas biografias. Assim, pelo domínio desses referenciais, a reivindicação de um assemelhamento passa a ser utilizado como um trunfo nas disputas que trava, servindo-lhe ainda como um reparo à carência de outros recursos identificados em nossa pesquisa como mais valorizados neste universo social, tais a titulação escolar, a inserção em importantes redes de relações sociais ou a experiência com "movimentos culturais" ou políticos em contextos de maior destaque nacional. Assim se observa no seguinte trecho:

Minha poesia, posterior à daqueles anos iniciais, fez-se influenciar, sobretudo, por paradoxal que seja, pela leitura apai- 
xonada dos grandes romancistas mundiais, como Dostoievski, com sua angústia metafísica e dolorosa consciência do mal, e Thomas Mann, pelo seu incurso nos domínios sombrios da morte e da arte. Minha poesia, seus sonetos que o digam, foge por completo aos cânones daquela geração ["geração de 45", considerada precursora do 'modernismo' no Maranhão], que reputo, contudo, importante pela expressividade de alguns nomes que a compõem [refere-se com freqüência a Lucy Teixeira, José Chagas, e Ferreira Gullar] ${ }^{5}$.

Quanto à relação entre os tipos de publicação de estreia e os principais cargos públicos ocupados ao longo de seus percursos sociais, observa-se que aqueles que iniciaram a carreira literária investindo em gêneros relacionados à economia ou ao direito, tenderam a ocupar postos mais próximos do pólo dominante da administração pública (Procuradorias, cargos de destaque em instituições voltadas à produção cultural, Secretarias e chefias de gabinetes etc.), mesmo que estes gêneros não se tenham afirmado como de maior relevância no decorrer de suas carreiras literárias.

Destaca-se o alto número de escritores que estrearam na literatura com a publicação de poesias e o pequeno número de ocupantes de altos cargos públicos entre eles, o que nos indica a existência de uma correlação entre as condições sociais de acesso a estes postos e a tendência a determinados tipos de produção literária, havendo inclusive pouca mobilidade entre o gênero da primeira publicação e os níveis dos cargos administrativos ocupados ao longo de suas carreiras literárias. Quanto a estas mudanças, destacam-se Jomar Moraes e José Sarney que iniciaram com o gênero poético e passaram a dedicar-se - embora não exclusivamente - a estudos biográficos e ao romance, respectivamente, inflexão que também acompanhou o destaque que adquiriram, na administração pública vinculada à produção cultural, no caso de Jomar Moraes, e no espaço do poder político, com José Sarney alçando à presidência

5 Entrevista concedida a Ricardo Leão em maio de 2003, disponível em: http://www. revista.agulha.nom.br/nauro1.html 
da República. Demonstra-se nos quadros abaixo a relação entre o gênero de ingresso na carreira literária e o nível dos mais altos cargos públicos por eles ocupados. Os textos de cunho jurídico e econômico foram agrupados no gênero científico. Antes, observe-se o quadro que demonstra os critérios utilizados para a hierarquização dos cargos públicos, conjugados ao número de agentes que ocuparam tais funções.

\section{Quadro 02 - Cargos públicos mais altos ocupados}

\begin{tabular}{|c|c|c|}
\hline \multirow{11}{*}{ Alto } & Cargos & $\mathrm{N}^{\circ}$ de casos \\
\hline & Chefe de gabinete (estado) & 1 \\
\hline & Chefe do Departamento Econômico do BNDE & 1 \\
\hline & Agente Fiscal de Tributos Federais & 1 \\
\hline & Secretário Geral do Conselho de Desenvolvimento (RS) & 1 \\
\hline & General do Exército & 1 \\
\hline & Auditor Fiscal de Rendas da Secretaria da Fazenda & 1 \\
\hline & Promotor Público & 1 \\
\hline & Chefe do Contencioso da Caixa Econômica Federal & 1 \\
\hline & Procurador Federal & 1 \\
\hline & Auditor Fiscal do Estado & 1 \\
\hline \multirow{9}{*}{ Médio } & Chefe da $3^{\circ}$ Inspetoria Geral da FUNAI & 1 \\
\hline & Direção de hospitais & 1 \\
\hline & Chefe de Gabinete (Município) & 1 \\
\hline & Reitoria da UFMA & 1 \\
\hline & Membro do Conselho Estadual de Educação & 1 \\
\hline & Direção da Secretaria do Tribunal de Justiça & 2 \\
\hline & Membro do Conselho de Contas do Município & 1 \\
\hline & Direção do IBAC & 1 \\
\hline & Membro do Conselho Nacional de Direito Autoral & 1 \\
\hline Baixo & $\begin{array}{l}\text { "Funcionário Público" (cargos pouco expressivos den- } \\
\text { tro da administração pública, como Redator, Porteiro, } \\
\text { Músico da Banda Militar, etc.) }\end{array}$ & 8 \\
\hline $\begin{array}{l}\text { Não In- } \\
\text { forma- } \\
\text { dos }\end{array}$ & & 9 \\
\hline Total & & 37 \\
\hline
\end{tabular}


Quadro 03 - Gênero da $1^{\circ}$ obra e nível do cargo público mais alto ocupado (\%)

\begin{tabular}{|c|c|c|c|c|c|c|}
\hline Gênero & $\mathrm{N}^{\circ}$ de casos & \multirow{9}{*}{ 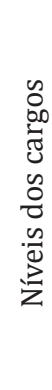 } & Altos & Médios & Baixos & Não informados \\
\hline Poesia & $22(59,4)$ & & $2(5,4)$ & $6(16,2)$ & $7(18,9)$ & $7(18,9)$ \\
\hline Romance & $3(8,1)$ & & $2(5,4)$ & - & - & $1(2,7)$ \\
\hline Ensaio & $4(10,8)$ & & $3(8,1)$ & $1(2,7)$ & - & - \\
\hline Teatro & $1(2,7)$ & & - & - & - & $1(2,7)$ \\
\hline Conto & $2(5,4)$ & & - & $1(2,7)$ & $1(2,7)$ & - \\
\hline Crônica & $1(2,7)$ & & - & $1(2,7)$ & - & - \\
\hline Científico & $4(10,8)$ & & $3(8,1)$ & $1(2,7)$ & - & - \\
\hline Total & $37(100)$ & & $10(27,0)$ & $10(27,0)$ & $8(21,6)$ & $9(24,3)$ \\
\hline
\end{tabular}

Fonte: repertórios biográficos

Outro dado relevante sobre o total de casos analisados trata da correlação entre os principais gêneros a que se dedicaram e os investimentos escolares feitos ao longo de seus percursos sociais. Aqueles que se encontravam mais propensos à dedicação a estilos mais exigentes literariamente (romances, poesia) tenderam a investir na formação escolar mais humanística, como filosofia, história, ou mesmo não chegaram a possuir formação superior - o que ocorre na maioria dos casos dedicados à poesia. Já entre os que se aplicam principalmente à publicação de ensaios, crônicas ou trabalhos científicos, tenderam a investir, a rigor, na formação em direito. Em grande parte descendentes de famílias atuantes no cenário político - algumas em processo de desclassificação social, outras de ascensão e afirmação enquanto classe dominante - estes "intelectuais" se situam através dos usos dos recursos, tangíveis e intangíveis, adquiridos por herança e dos investimentos em títulos escolares e inserções em movimentos de cunho cultural e/ou político, atendendo às condições e possibilidades estabelecidas pelas transições políticas daquela conjuntura, em nível nacional e "local". Entre os que não são membros da AML (18, correspondente a 48,6\% do total) é predominante a titulação escolar em nível superior (5) e 2 casos com pós-graduação. Além destes, 2 possuem nível fundamental e 4 escolaridade em nível Médio. Sobre 5 deles não obtivemos 
informações quanto à sua escolaridade. Quanto à titulação escolar entre os membros da AML, dividem-se em 1 com nível fundamental, 3 com nível médio e também prevalece a formação superior com 7 casos e outros 2 com pós graduações. Também é aproximado o número de casos não informados, 6.

\section{Socialização, sociabilidades e constituição de sentidos}

Além da importância que adquire a capital do estado como principal centro de investimentos escolares feitos por estes agentes, outro elemento que contribuiu para que se concentrassem nesta cidade os "vocacionados" à "literatura", processo iniciado ainda na Primeira República com os Novos Atenienses (Cf. NASCIMENTO, 2011; MARTINS, 2006; BORRALHO, 2011), foi a aglutinação dos principais serviços de imprensa, que se constituíram em espaços privilegiados de atuação destes "intelectuais", bem como a possibilidade de inserção em "movimentos culturais", coalizões e a proximidade com importantes espaços de publicação também livresca, fossem de domínio público (Serviço de Imprensa e Obras Gráficas do Estado, Secretaria Estadual de Cultura do Maranhão, Fundação de Cultura do Maranhão etc.) ou privados aos grupos faccionais, como as revistas, jornais, editoras etc. todos com destacada concentração em São Luís. Tomemos a localização dos jornais identificados no acervo da Biblioteca Pública Benedito Leite e que circularam durante o período de 1945 a 1964 como demonstração desta centralidade: dos 68 jornais, 52 $(76,4 \%)$ localizavam-se em São Luís (Cf. SILVA, 1981).

A atuação jornalística confere à maioria dos agentes em questão (25) um status equivalente ao de "intelectuais": ao passo que por seu intermédio podem glosar-se na reivindicação e críticas das pautas legítimas, também lhes enseja a publicação de crônicas, contos, poesias e outros gêneros próprios à literatura, e por meio destes afirmam-se e distinguem-se literária e faccionalmente. Além disso, servem-lhes os jornais como importantes espaços de "sociabilidades e socialização, de tomadas de posição 
e criação de vínculos variados etc. de cristalização de lógicas de identificação e competição" (REIS, 2007, p. 163).

\section{Movimentos Culturais e Engajamentos Políticos}

Os "movimentos literários" dos quais participaram os agentes analisados cumprem dois importantes papéis relacionados às observações feitas acima. Por um lado servem aos agentes como espaços de mobilização e constituição de coalizões que se caracterizam, como observa Boissevain, pela fragilidade das organizações internas, das interdependências e compromissos mútuos entre os indivíduos, sua instabilidade, efemeridade e concentração, principalmente em seu formato faccional, na figura de um líder (BOISSEVAIN, 2003). Através dos usos dos recursos sociais que dispõem, os membros destas coalizões agem, atendendo a seus objetivos momentâneos, constituindo repertórios próprios em torno de noções estético-literárias, políticas e ideológicas, que implicariam, portanto, na reivindicação da posse legítima dos modos de ser e do "estilo literário" do autêntico "ser-poeta”, além de outras noções reivindicadas. Por outro lado servem como importantes espaços de socialização e constituição de sentidos, promovendo uma certa homogeneidade entre os grupos diversos, ainda que atendendo a interesses esporádicos, em torno de crenças e afinidades práticas e literárias (gostos culturais, discussões em torno dos grandes autores etc.). Importa ressaltar que não apenas estes "movimentos" serviam à construção e partilhamento das dinâmicas de pertencimento e gozo de sociabilidades (REIS, 2007), também os encontros corriqueiros, tão informais quanto frequentes, devem ser percebidos como importantes espaços de socialização e constituição de redes sociais em torno da produção cultural. Ilustra um pouco esta assertiva o trecho seguinte: 
éramos três irmãos aqui, durante anos e anos nós bebemos [...] o Chagas é um grande poeta, basta dizer que ele é o autor do Canhões do Silêncio, aquilo vale tudo, aquilo abrange todo aquele bairro do desterro, as madames, as meretrizes, ele abarca tudo isso. O Almeida também foi um grande pintor, um intuitivo, porque não tinha uma formação, vamos dizer, "acadêmica", mas era outro também que lia! O Almeida leu uma vez o Thomas Mann, rapaz, José e Seus Irmãos, ele lia aquilo e discutia até com as prostitutas e conversava com elas, sabe sobre o que? Modigliane e sobretudo Jesus Cristo! [...] Nós passamos a mocidade no Bar do Castro, no Hotel Central, no Bar do Pataquinha, mais de quinze ou vinte bares que existiam aqui [...] nós bebíamos e conversávamos sobre cinema, literatura, artes plásticas, música, Erasmo Dias não saía do Bar do Castro, nem Erasmo nem Bernardo Coelho de Almeida $[\ldots]^{6}$.

Também a "drenagem dos produtores da capital" (CHARLE, 1977), conjugada às experiências sociais trazidas de fora do estado, e em alguns casos de outros países, possibilitou algumas transformações e o estabelecimento de novos referenciais literários e consequentemente a valorização e produção a partir de novos estilos e formas. Se em meados do século XIX temos presente na literatura maranhense a valorização do simbolismo, parnasianismo e do romantismo presentes na evocação de poetas como Castro Alves, Paul Verlaine, Charles Baudelaire e Camões, os referenciais do vigésimo século - tomados a partir dos agentes aqui analisados - são, em sua maioria, identificados pelo modernismo, realismo, concretismo e neo-concretismo, reverenciando-se autores como Fernando Sabino, Flaubert, Dostoievski, Edgar Allan Poe, Thomas Mann, Paulo Mendes Campos, entre outros.

Neste embate entre forças de conservação e de renovação em torno da "literatura", pretende-se impor, junto aos estilos reivindicados, um panteão que os referencie e diferencie, seja reivindican- 
do-se seus herdeiros ou epígonos nos casos mais tradicionais, ou investindo contra os vultos estabelecidos exigindo sua substituição. Quanto ao primeiro caso é exemplar a forma como se estrutura a AML e o IHGM em sua relação com os Patronos, Fundadores de Cadeiras e Ocupantes, cuja genealogia funciona à espécie de um sistema de parentesco, conforme descreve Alfredo Wagner:

Tem-se um conjunto de autores, representados como personalidades e figuras tutelares da historiografia regional, que ampara a criação das cadeiras e seus respectivos fundadores e demais ocupantes. Por disposições estatuárias a cada cadeira corresponde um patrono, uma figura como "autoridade em história, ou geografia e ciências afins", e um fundador, que representa aquele que evoca o patrono ao criar um assento na instituição. 0 nome dos patronos jamais poderá ser substituído pelos vindouros ocupantes das cadeiras conforme reza o art. 31, § Segundo[Regimento Interno da AML]. Seus nomes mantêm vivas e encarnam os fundamentos das tradições letradas, permitindo aos que aspiram lugares nos panteons e galerias de "vultos maranhenses" uma relação em linha direta com os seus protetores (ALMEIDA, 2008, p. 29).

Ocorre ainda que, condicionadas as lógicas de concorrência e as estratégias de afirmação à interferência de princípios externos, os agentes geralmente transitam por vários movimentos buscando melhor posicionar-se através dos usos do exercício literário combinados a outros domínios, sendo a política o principal deles. Entre os 37 agentes analisados, tivemos 19 participantes deste tipo de mobilização para 7 movimentos identificados, 0 que aponta para um intenso trânsito dos agentes por estas estâncias, apesar de uma relativa variedade das temáticas reivindicadas pelos "movimentos culturais". Preferimos utilizar o termo "cultural", em seu sentido mais genérico, por não se vincularem todos estas mobilizações estritamente ao exercício literário, mas corresponderem a várias modalidades de ação (literatura, teatro, artes plásticas etc.) e temáticas (cultura do Maranhão, meio 
ambiente - a exemplo do Movimento em favor da Ilha, capitaneado por Nascimento Morais filho - etc.). Ressaltamos que sobre o total de casos analisados não obtivemos informações relativas à participação em "movimentos culturais" de 16, e sabe-se que 2 dentre os 37 casos analisados não participaram de qualquer organização desse tipo.

Quadro 03 - Movimentos culturais*

\begin{tabular}{l|c}
\hline Nome & $\mathrm{n}^{\circ}$ de casos \\
\hline Centro Cultural Gonçalves Dias & 9 \\
\hline Grupo Movelaria & 5 \\
\hline Grupo Ilha & 3 \\
\hline Afluente & 3 \\
\hline Opinião & 1 \\
\hline Apolônia Pinto & 2 \\
\hline Nenhum (declarado) & 2 \\
\hline Não informados & 16 \\
\hline *Alguns casos se inserem em vários movimentos \\
\hline
\end{tabular}

Fonte: repertórios biográficos

Este tipo de mobilização deve ser compreendido à luz da conjuntura em que se estabelece. Outrossim, superado o chamado Estado Novo, que no Maranhão transcorre sob a interventoria de Paulo Ramos, destacam-se entre os "intelectuais" expoentes e os "movimentos" em que se engajavam, nomes como os de José do Nascimento Morais Filho, José Sarney e Bandeira Tribuzi (todos contidos entre os casos aqui analisados), reconhecidamente lideranças do Centro Cultural Gonçalves Dias, Grupo Ilha e Grupo Movelaria Guanabara, respectivamente. No interior destes "movimentos" destacam-se, vinculados ao Centro, Bernardo Coelho de Almeida, Nascimento Moraes Filho, Vera-Cruz Santana, Manuel Sobrinho, Tobias Pinheiro, Dagmar Desterro, Ferreira Gullar, Lago Burnett, Bandeira Tribuzi - deslocando-se logo de- 
pois para o Grupo Ilha. Em torno deste último transitavam José Sarney, Bello Parga, Carlos Madeira e Lucy Teixeira. Quanto ao Movelaria Guanabara, uniram-se Antonio Almeida e Lago Burnett, que até então compunha o Centro Cultural Gonçalves Dias.

Tais agentes utilizam como principal estratégia de afirmação no domínio literário a reivindicação de representantes da "nova literatura maranhense", em posse de novos recursos e trunfos, alguns deles adquiridos em experiências fora do estado e no exterior. Como exemplo podemos destacar alguns elementos presentes no perfil de Lucy de Jesus Teixeira, observados por Arlete Nogueira da Cruz Machado: "recém chegada de Belo Horizonte onde se formara em Direito, amiga dos melhores intelectuais mineiros de então, e consciente das modernas conquistas literárias de seu tempo" (CRUZ, 2003, p.36). Nascida em Caxias, Lucy residiu na Europa pela primeira vez como bolsista do Governo italiano. Regressou a São Luís em meados da década de 40 e a partir de então promoveu diversas atividades literárias e de artes plásticas. Muda-se para o RJ em 1949, continuando a publicar em jornais e a colaborar com diversos suplementos literários, a exemplo de sua longa atuação no jornal 0 Imparcial, de São Luís. Além de participar do grupo Movelaria Guanabara, organizou em São Luís, com Ferreira Gullar, o Congresso Súbito de Poesia, do qual resultou a fundação do Movimento Anti-Quentismo, segundo ela "de repúdio ao sentimento fácil em poesia”, foi também uma das fundadoras do Grupo Ilha, do qual também participaram Bandeira Tribuzi e José Sarney. Formada em direito pela UFMG, dedicou-se principalmente à produção de crônicas e poesias; ocupante da cadeira $\mathrm{n}^{\circ} 7$ da AML (recebida por José Sarney); ocupou também importantes cargos públicos, destacando-se o de Diretora da Secretaria do Tribunal de Justiça do Maranhão.

À época do que a historiografia e crítica literária local passaram a denominar de "modernismo literário" no Maranhão - entre os anos de 1945 e 1950 -, inicia-se o período etiquetado (GRILL, 2010) por "oligarquia vitorinista". Tais epígrafes consagradas 
pela historiografia local às diversas fases da política maranhense não têm por fortuitas suas origens e podem nos fornecer importantes elementos para compreendermos os usos estratégicos da memória e das referências ao passado como forma de coesão dos grupos em torno de um passado comum reivindicado.

Como mencionado acima, este processo acompanha o ascenso de uma nova geração e rearranjos faccionais e pressupõe a consagração de um novo panteão que, sob os auspícios de epígonos e continuadores dos seus feitos heróicos, redefinem seus posicionamentos em torno de determinadas problemáticas e suas respectivas posições e oposições. Assim ocorre com os usos das terminologias "magalhãesistas", "vitorinistas", "oposicionistas", "ilha rebelde", "Atenas brasileira", "decadentismo", entre outros, em torno dos quais aglutina-se um conjunto de agentes ou vinculam-nos seus opositores: no primeiro caso como estratégia de afirmação faccional, no segundo também como afirmação, porém a partir da desqualificação e estigmatização do grupo oposto, a exemplo da categoria "vitorinismo" enfatizada pelos oposicionistas, caracterizando-os como apoiadores de uma oligarquia que já adentrava sua segunda década de mandonismo local, contrário às tradições maranhenses de um passado de lutas pela liberdade e "dependente das fraudes eleitorais para permanecer no poder" (CRUZ, 2003, p. 44).

Como observa Igor Grill, estas etiquetas acionadas nas disputas intelectuais e políticas no Maranhão

[...] são categorias ativadas como critérios de aproximação e de estabelecimento de clivagens, mediante as quais as lutas faccionais que atravessam o espaço da luta política no plano estadual se definem e redefinem [...] (GRILL, 2010, p. 1).

Envoltos pela atmosfera de disputas faccionais entre "vitorinis- 
tas" e "oposicionistas" que (de)marcaria a historiografia maranhense, os "intelectuais" da segunda metade do século XX não hesitaram em se posicionar fazendo uso de suas "vocações literárias", dando prosseguimento à tarefa herdada dos protagonistas políticos de outrora nas lutas pela libertação do Maranhão, em direção à retomada do seu mítico passado glorioso, de exuberância econômica, política e cultural, cujo significado é constantemente reinventado conforme se rearranjam os grupos em disputa. Esta observação ganha relevância para este estudo ao percebermos que, no universo analisado, as principais posições dentre os cargos eletivos e da administração pública são ocupados por figuras proeminentes nas disputas faccionais, aliadas ao grupo dos oposicionistas, que se impôs na posição de dominante no espaço do poder político maranhense.

\section{Lieux du Milieux}

Os espaços de publicação recebem aqui o tratamento de lugares (lieux), no sentido empregado por Eliana Reis, como espaços de "expressão oficial dos grupos" (REIS, 2001, p. 25) e de criação de laços de identificação, vínculos afetivos e sociais entre os agentes (milieu). Estes lugares apresentam-se, portanto, como fontes privilegiadas para a análise do trabalho de construção da memória dos agentes e grupos que por eles ligavam-se, afirmavam-se e se distinguiam por coalizões distintas.

Entre estas alianças, destacam-se as facções em torno de movimentos políticos e literários, que propiciavam também o controle de importantes espaços de publicação, ensejando inclusive o ingresso de diversos autores na carreira literária. A exemplo da importância desses espaços de afirmação temos a Tipografia São José, da Arquidiocese de São Luís. Gerenciada por Bernardo Coelho de Almeida - entrementes incluído entre importantes estreias como as de José Chagas, Nauro Machado, Nacedo Neto, Manuel Lopes e Nascimento Moraes Filho -, fundador da revista 
Legenda e também publica várias obras de colaboradores desta reviosta no período analisado, além de lançar outros livros de estreia, como o de José Chagas, Canção da Expectativa (1955). Pelo Centro Cultural Gonçalves Dias Lago Burnett lançou sua primeira obra, Estrela do Céu Perdido (1949) e através da revista Afluente edita alguns livros de sua autoria, como 0 Ballet das Palavras (1951) e Os Elementos do Mito (1953). Além destas, Voz no Silêncio, de Manuel Lopes (1953); Canção Inicial, de José Sarney (1954) e Iceberg de Macedo Neto (1955). Há também os que não chegaram a publicar, mas participavam dos conselhos editoriais organizados por estes espaços, é o caso de Luís Carlos Bello Parga, que integrava o conselho editorial da revista Ilha, Fundada pelo Grupo Ilha, sob as lideranças de José Sarney e Bandeira Tribuzi, da qual também participava Lucy Teixeira. No entanto, as vinculações destes agentes a determinados lugares e "movimentos culturais" devem ser analisadas relacionando-se os demais posicionamentos tomados em domínios diferenciados e considerados estrategicamente como oportunidades para o estabelecimento de alianças que retroalimentam suas variadas formas de atuação - facilidades de publicação, nomeação para cargos públicos etc. Desta forma a ocupação de cargos públicos vinculados a atividades culturais como a Secretaria de Cultura, FUNC, SIOGE, Conselho Estadual de Cultura e o IPHAN, constituem-se em estratégias privilegiadas para as relações de aliança faccional, que implicam em relações de trocas e retribuições entre estes "intelectuais", no trânsito entre os domínios político e literário. Assim considerados, justifica-se o percentual elevado dos agentes que ocuparam tais funções administrativas, buscando através do granjeamento das instâncias culturais do estado, condições de sobrevivência, econômica e principalmente literária, que um contexto como o maranhense, sem uma relativa autonomia deste espaço, não lhes poderia ofertar.

Outra importante estratégia utilizada pelos agentes, principalmente em posições mais dominadas no processo de afirmação intelectual, é a referência a nomes consagrados, transferindo para si a valorização de princípios, recursos e práticas que se 
sabem deles. É exemplar o artigo produzido por Nauro Machado por ocasião do falecimento do escritor Nascimento Moraes Filho, neste, além de referir-se diretamente ao autor, insere comentários de outros escritores consagrados. Cabe ainda observar a ocorrência de uma espécie de "divisão e hierarquização do trabalho social de consagração, de retribuição e de apropriação coletiva dos feitos do homenageado" (GRILL, 2010, p. 8). Seguem alguns fragmentos do referido artigo:

Nauro Machado: Comigo ele [Nascimento Moraes] foi exemplar por toda a sua vida, citando-me o nome como o de um grande poeta, no exagero que lhe era peculiar, defendendo-me todas as vezes em que eu era atacado na minha vida pública, aconselhando-me, o que fez por inúmeras vezes, para ir morar no Rio de Janeiro, onde, dizia ele, eu teria meu renome assegurado como escritor e poeta.

Ferreira Gullar: Mais que todos nós, era Nascimento Morais o que tinha maior consciência das questões sociais e já então fazia da sua poesia instrumento de luta em defesa dos interesses nacionais.

Arlete Nogueira da Cruz Machado: Depois do movimento que liderou, a partir de 1945, Zé Morais publicou vários livros, entre eles Clamor da Hora Presente, que será lançado hoje na sua quarta edição. Poeta, professor, autêntico cidadão, estimulador de talentos, defensor dos injustiçados, veemente voz contra ímpios poderosos, incansável pesquisador, acabou por descobrir a primeira romancista maranhense, Maria Firmina dos Reis, apresentando-a ao Mundo através de festa memorável ${ }^{7}$.

Outra observação a ser destacada nestes recortes é a semelhança entre os elementos enfatizados acerca do mesmo sujeito referente e as respectivas posições ocupadas pelos agentes. Assim, Nauro Machado salienta as relações pessoais com o homenage- 
ado, lembrando os elogios que dele recebia como "grande poeta", além de protetor dos ataques que sofrera na vida pública e conselheiro insistente de sua mudança para o Rio de Janeiro onde teria seu "renome assegurado como escritor e poeta". Em seguida, Ferreira Gullar enfatiza o pertencimento ao mesmo grupo (refere-se aos movimentos Movelaria Guanabara e Centro Cultural Gonçalves Dias) e destaca o engajamento de sua poesia, voltando-a para os problemas sociais e dos interesses nacionais, muito semelhantes às principais características enfatizadas em suas biografias. Por fim, Arlete Nogueira da Cruz realça a principal função que cumpriu à frente da SECMA na publicação de vários trabalhos de maranhenses, exaltando o homenageado como "estimulador de talentos".

Também acompanham as intervenções de Nauro Machado o que poderíamos chamar, como Bourdieu, de "dialética do ressentimento que condena no outro o que deseja para si próprio" (BOURDIEU, 2002, p. 32), manifesta pelo rechaço frequente dos escritos e projetos dos acadêmicos que, segundo ele, "literariamente não significa[m] nada porque não têm atuação literária". 0 anverso desta postura é sua angústia por um reconhecimento local, sempre refreado pela resistência à popularização da sua poesia, em falas que a esta recusa mescla-se a satisfação por um sempre reafirmado reconhecimento nacional e internacional, como os verbetes relativos à sua poesia presentes em alguns dicionários internacionais de literatura:

[...] eu tenho atualmente, existem leitores fora daqui, leitores muito bons, lógico né, mas só quem me conhece. Algumas pessoas sérias que escreveram sobre a minha poesia, eu faço parte de boas antologias, inclusive algumas na Europa [...] eu tenho bons amigos poetas, colegas que me respeitam como poeta, um exemplo: Ivan Junqueira, você conhece, não conhece? Foi até presidente da Academia Brasileira de Letras, isso não significa muita coisa, ser presidente da... mas ele é um grande poeta, traduziu tudo do T.S. Eliot, 
Baudelaire e Émille Thompson. [...] o Carlos Drummond de Andrade respeitava muito minha poesia, pessoalmente dei duas carreiras nele na Cinelândia, eu bêbado, 1958, ele era mineiro, caladão [...] (loc. cit., p. 14).

O projeto embargado de reprodução da notoriedade familiar se manifesta na sua carreira literária como uma "revolta submissa" (Idem, p. 33) às posições medíocres impostas conjunturalmente. Assim, sua auto-apresentação reporta-se sempre a nomes consagrados internacionalmente na literatura, conjugando a esta característica a tentativa de assemelhação entre suas biografias, não sendo, portanto, fortuitas as eleições, para seu trabalho de auto-representação, de autores como Fernando Pessoa ou Charles Baudelaire, conforme os trechos de entrevistas:

[...] todo o espaço literário dele [Fernando Pessoa] ficou circunscrito àquele pequeno espaço por ele habitado pro resto da vida, do tempo dele que ele passou em Lisboa, apenas alguns quilômetros quadrados, e o meu próprio espaço também está restrito quase que exclusivamente a esta parte tradicional que é a parte de São Luís, aqui projeto Praia Grande até mais ou menos Desterro [...] (Ibdem).

Nauro Machado não participou de qualquer "movimento cultural" e insere-se no perfil dos que ocupam os cargos públicos mais baixos, caracterizado principalmente pelo baixo grau de escolaridade; não teve experiências nacionais ou internacionais que poderiam ser utilizadas como trunfos (formação superior em outros estados, convívio com personagens expoentes do modernismo, exílio etc.) - mesmo não se tratando de formação superior, a breve passagem de um semestre pelo colégio Mallet Soares, no Rio de Janeiro, é mencionada com destaque em suas sínteses biográficas (Cf. p.ex. RAMOS, 1990; BRASIL, 1994) -, também não é membro de nenhuma instituição dedicada à consagração intelectual. Este conjunto de informações funda- 
mentam a importância das relações pessoais, de compadrio ou parentesco, para o granjeamento do cargo que ainda hoje ocupa junto à Secretaria de Cultura do Maranhão, o que se demonstra nestas falas:

Certa vez, naquele mesmo Canto do Protesto, Zé Moraes verberou contra a minha não permanência em um cargo comissionado da Secretaria da Cultura do Maranhão, criada por iniciativa da escritora Arlete Nogueira da Cruz, indo falar pessoalmente depois com o então Governador Luís Rocha, seu velho amigo, dele conseguindo (graças também à defesa que me fizeram vários intelectuais, como o nosso querido e grande ensaísta Franklin de Oliveira e de alguns membros da Academia Brasileira de Letras, e outras associações literárias) que o recém nomeado Secretário da Cultura voltasse atrás, conservando-me ainda como Assessor daquele órgão cultural.

Ou quanto às homenagens que tem recebido:

Mas a verdade é que de alguns anos para cá, sobretudo a partir do governo da minha querida amiga, senadora Roseana Sarney Murad, ganhei o reconhecimento oficial dos meus conterrâneos, sendo até mesmo nome de praça e tema da Escola de Samba Turma do Quinto, que ganhou o carnaval de São Luís no ano passado [2002], com um enredo baseado em minha vida e poesia (loc. cit., p. 6).

Na ausência de destacados recursos econômicos, titulação escolar, ou de experiências valorizadas por momentos de crises políticas (cf. REIS, 2007), Nauro Machado investe estrategicamente na importância política de seus ascendentes e no domínio de referenciais artísticos (literatura, artes plásticas, cinema, música etc.) como trunfo:

Você sabe que o nosso sobradão, que é o sobrado da família 
Machado foi ocupado pelos chamados "soldados da liberdade", tomaram conta do sobrado, da praça [do Largo do Carmo] toda foi tomada pelo povo, se alimentavam na praça, você deve saber dessa história toda, né. Por quase um mês [...] o porto não funcionava, a marinha não funcionava [...] a cidade parou completamente [...] e aquele sobrado era do meu pai, minha mãe era viúva e cedeu o sobrado para o Neiva Moreira, ficou como chefe desse movimento, ele e o meu tio General Lino Machado, o Lino você sabe, irmão do Marcelino Machado, tem a ponte Marcelino, do Partido Republicano, genro único de Benedito Leite [...] tanto que tem a ponte hoje do Benedito Leite e tem a do lado a ponte Marcelino Machado, a rodoviária se chama Marcelino Machado. Aquele foi um movimento fabuloso, um momento sério contra a posse do Eugênio. [...] desde aquela época [década de 50], ali ao lado [do Largo do Carmo] havia uma livraria, a livraria Universal que era [...] a livraria mais antiga do país, e que através desta livraria eu tive a oportunidade de ler praticamente tudo que a livraria dispunha lá, do Raimundo de Almeida. Tive esta sorte, de ler sobretudo os franceses, dinamarqueses e caperva, né. Proust, Balzac, Zola, que eu gostei muito do Zola, Scandinavo, Strindberg, Flaubert, dos ingleses também: Dickson, li muito Dickson, por incrível que pareça, que reputo ser um grande romancista, que eu acho fabuloso também, e sobretudo [...] um poeta chamado Edgar Alain Poe, que me influenciou muito. Basta dizer também que ele influenciou quem: os dois monstros da literatura francesa, né: Baudelaire e Stéphane Mallarmé, sobretudo Baudelaire que traduziu todos os Contos Extraordinários para o francês e até hoje, por incrível que pareça, incrível numa maneira crítica com que eu vejo as coisas, quem sou eu para me equiparar, ao menos me rastejar perto dos grandes críticos norte americanos que consideram o Edgar Alain Poe de "segundo time" da literatura, você sabia disso, sabia? Enquanto os franceses reputam Edgar Alain Poe como um grande mestre, que foi influenciador, em parte, do movimento simbolista francês, através do Baudelaire, Stéphane Mallarmé[...] Filosofia e cinema também, que eu sempre fui apaixonado pelo cinema, desde jovem eu não saía do cinema, do Éden e do Rox, outra sorte minha porque grandes filmes passavam aqui [...] conheci filmes da Worm da United, da Mezzo, do neorealismo italiano, da França Filmes, da 
Art Filmes, todos esses passavam aqui, eram lançados quase que simultaneamente aqui e no Rio de Janeiro [...] mas eu acho que eu tive essa sorte de viver através disso, de certa maneira, porque você sabe que a imaginação às vezes vale mais do que a realidade, né poeta (loc. cit., p. 20).

"Já disse dezenas de vezes, em circunstâncias as mais diversas, que só poderia ter escrito esses milhares de versos que compõem meus trinta e seis títulos de poesia já publicados, vivendo em São Luís". Assim Nauro Machado inicia o prefácio de sua trigésima sexta obra: "Pátria do Exílio" (2010). Título indicativo de uma das suas principais, e paradoxais, reclamações, ou seja, o fato de sempre ter vivido em São Luís. 0 paradoxo se deve ao desejo manifesto de vivência em regiões mais centrais e o reconhecimento de que o conteúdo de seus poemas se deve principalmente a este "enclausuramento".

[...] pelo mastigar de um Pão Maligno com Miolo de Rosas (MACHADO, 2008, p. 43-97) como a explicar os lados externo e interno daquilo que constitui meu alimento verdadeiro, que é a cidade de São Luís e o verbo que em mim transformo num miolo de rosas, que desejo ser o coroamento do meu esquife poético, até chegar ao paraíso utópico que jamais vislumbrarei pela visão material do meu tato humano, visto se contemplado apenas à distância, através de uma Lisboa por mim tanto desejada e na qual meus pés reais jamais, tenho certeza, haverão de pisar (MACHADO, 2006).

Diferentemente de Nauro, Ferreira Gullar é aquele que migra da periferia para o centro nacional. Filho de pequenos comerciantes de São Luís, engajou-se em importantes "movimentos culturais" e políticos como o Centro Cultural Gonçalves Dias (através do qual publica seu primeiro livro, Um pouco acima do Chão - 1949), Grupo Afluente, Movelaria Guanabara, e liderou junto a Lucy Teixeira o Movimento Anti-quentismo, todos 
estes no contexto maranhense. Em 1962 ingressa no Centro Popular de Cultura (CPC) da União Nacional dos Estudantes (UNE), sendo eleito seu presidente em 1963. Em contato com importantes personagens no domínio cultural nacional, como Oduvaldo Vianna Filho, Paulo Pontes, Armando Costa, Thereza Aragão, João das Neves, Denoy de Oliveira e Pichin Pla, funda com estes o Grupo Opinião em 1964. Trabalhou como locutor da rádio Timbira (que pertencia ao Governo Estadual), na revista do Instituto de Aposentadoria dos Comerciários, como revisor de textos na revista 0 Cruzeiro (1951) e colaborou no suplemento literário do Diário de São Luís. Já no Rio de Janeiro, trabalhou como Revisor (e depois redator) na revista Manchete. Depois de trabalhar como redator no Diário Carioca, Gullar integra a equipe que elabora o Suplemento Dominical do Jornal do Brasil (1955). Passa a trabalhar em 1962 como redator na sucursal carioca de 0 Estado de São Paulo, jornal ao qual estaria ligado por quase 30 anos. Em 2004 passa a assinar uma coluna semanal de crônicas no Caderno Ilustrado da Folha de São Paulo. Exilado em 1971 pelo Golpe militar sob a acusação de pertencer ao Comitê Cultural do PCB, partido ao qual se filiara em 1964 (período em que exercia a direção da Fundação Cultural de Brasília), morou em Paris, Moscou, Chile e Buenos Aires, onde escreve, em 1975, seu célebre Poema Sujo (1976), trazido ao Brasil e divulgado por Vinicius de Moraes. Em 1992, Ferreira Gullar é Nomeado pelo Presidente Itamar Franco diretor do Instituto Brasileiro de Arte e Cultura (IBAC), cargo em que permaneceria até 1995.

É interessante notarmos a apropriação da obra deste autor como se houvesse um fio condutor a conectar ideologicamente seu ingresso na carreira literária e o reconhecimento alcançado na maturidade. Ainda outro elemento digno de destaque são as diferentes interpretações da "obra" ou de um "texto" específico de um determinado "autor" a partir das posições ocupadas por seus intérpretes. Assim, enquanto para Otto Maria Carpeaux o Poema Sujo representa 
A encarnação da saudade daquele que está infelizmente longe de nós, geograficamente, e tão perto de nós como está perto dele, na imaginação do poeta, o Brasil que lhe inspirou esses versos. Poema sujo mereceria ser chamado 'Poema nacional', porque encarna todas as experiências, vitórias, derrotas e esperanças da vida do homem brasileiro. É o Brasil mesmo, em versos 'sujos' e, portanto, sinceros (In: GULLAR, 2004).

\section{Para os comentadores maranhenses, esse mesmo poema recebe outros adornos:}

Portanto, no exílio, noutro momento desesperado e vital, quando entende que poderá morrer a qualquer instante, é que nasce o orgástico, o delirante, o vertiginoso Poema Sujo, cuja centralidade está novamente no seu chão de origem. Nenhum livro deste poeta nasce de situação mais vital e horrenda. Sabia-se, por exemplo, que a ditadura na Argentina, onde Gullar se encontrava na época, estava seqüestrando seus opositores e explodindo-os dentro de carros. E, então, o poeta Ferreira Gullar mais uma vez se volta para a mitologia pessoal de José Ribamar Ferreira. Mais uma vez, das pedras-memória, da estopa e dos ventos, do tesou-monturo, do lodo e azulejo, do turvo e azul de sua formação em São Luís o poeta fixará firmemente neste poema seu locus e seu ser, que são um só. (In: 0 Guesa Errante, edição 221).

Toda a trama elaborada pela crítica literária maranhense acerca de Ferreira Gullar se tece abaulado sobre um baú de memórias de sua terra natal. Vejamos alguns exemplos presentes em nota editorial de publicação do Suplemento Cultural e Literário JP Guesa Errante, publicado por ocasião do $80^{\circ}$ aniversário de Ferreira Gullar:

Não é fácil criar a biografia de um homem que chega à idade de oitenta anos, principalmente se esse homem for um cidadão brasileiro, nascido no Maranhão, mais precisamente 
na cidade-ilha de São Luís do Maranhão, especificamente numa casa com quitanda e quintal, na Rua dos Prazeres, esquina com Afogados [...]. principalmente porque lendo as obras completas desse poeta, se tenha a estranha sensação de que ele, apesar de haver vivido fora de São Luís, desde os vinte e um anos de idade, nunca haja saído daquela casa com quitanda e com quintal. Principalmente se esse homem for o escritor Ferreira Gullar, que sacou que, para vir a ser poeta, não precisava de um grande espaço geográfico. Só precisava do espaço pequeno de sua casa com quitanda e com quintal de onde pôde ler o mundo. Aos vinte e um anos pôs tudo em miniatura no cérebro e no coração. Pôs a casa, pôs a quitanda, pôs o quintal, depois foi pondo o que estava dentro da saudade e não quis deixar para trás [...] até que ao final percebeu que na bagagem estava todo o mapa da cidade incluído. [...] Achou prudente, por isso, guardar seus bens de cabeça e coração nalgum lugar mais seguro, onde pudesse preservá-lo para o presente e para o futuro. Colocou-os em poemas. [...] Principalmente se esse poeta cantou sua casa, com quitanda e quintal em obras-primas geniais como A Luta Corporal, O Vil Metal, Dentro da Noite Veloz, Na Vertigem do Dia, Poema Sujo, Crime na Flora, Barulhos e Muitas Vozes e através delas universalizou São Luís do Maranhão, ilha onde nasceu, no dia 10 de setembro de 1930, na Rua dos Prazeres, esquina dos Afogados.

É notório o investimento em voltar sua poesia para sua cidade-ilha, onde viveu seus primeiros anos. Tudo se cristaliza: a cidade, a rua, a casa, o poeta. E se reivindica deste cosmopolita todas as menções ao passado como sinônimo de seu enraizamento à terra natal que frutifica sua poesia. Convém, no entanto, observar, com certo tom de ironia, que a publicação de Toda Poesia (2004), organizado pelo próprio autor, exclui de sua antologia seu livro de estreia, Um Pouco Acima do Chão (1949), único editado em sua terra natal, dois anos antes de mudar-se definitivamente para o Rio de Janeiro.

Ocorre que são diversas as inflexões presentes na trajetória social e intelectual de Ferreira Gullar, seja quanto aos "estilos" ou 
modalidades de sua "obra", tais como apontadas no item "obras do autor" da mencionada antologia (poesia, contos livros infantis, ensaios, teatro, crônicas, ficção, memórias e biografia).

O objeto de saudosismo alegado a um (Ferreira Gullar) é a angústia pelo isolamento do outro (Nauro Machado). 0 que partiu há sessenta anos é reivindicado, através de seus poemas, como o que, "apesar de haver vivido fora de São Luís, desde os vinte e um anos de idade, nunca haja saído daquela casa com quitanda e com quintal"; o que jamais migrou para o centro (Nauro Machado), reclama uma poesia voltada pra fora, resignada pelo enraizamento em São Luís: "a melhor viagem mesmo é a de quem fica” (loc. cit., p. 22); quase sempre comparado a personagens de reconhecimento internacional, como exemplo a referência de Ricardo Leão: “Comparado a Fernando Pessoa, Nauro possui uma obra realmente singular, distinto de qualquer poeta contemporâneo, mesmo de sua geração" (BRASIL, 1994).

Tendo em mente o que se observa acima, vejamos, a guisa de exemplo, as diferentes relações estabelecidas por Nauro Machado e Ferreira Gullar com São Luís, a partir de suas "canções de exílio: 


\section{Canção do (D)Exílio}

Não permita Deus que eu morra

Nesta terra em que nasci:

Que a distância me socorra

E com turbinas me corra

De quem minha nunca cri.

De quem, minha, foi madrasta

Desde o início ao anoitecer,

E que como gosma emplastra

0 infinito me desastra

Meu desespero de ser.

Nosso céu tem mais estrelas,

Nossos bosques têm mais vida.

Mas, somente a merecê-las,

Têm a córnea pervertida.

Nosso céu tem mais primores

Quando o crepúsculo baixa:

São os mendigos e as suas dores

Carregadas nos andores

Como defuntos em caixa.

Onde cantou o sabiá,

Cantou outrora a cotovia.

E hoje canta, em outro ar,

Nenhuma ave, que as não há

Nesta terra, morto o dia.

(In: MACHADO, 2008)
Volta a São Luís

Mal cheguei e já te ouvi gritar pra mim: bem te vi!

E a brisa é festa nas folhas

Ah, que saudade de mim!

0 tempo eterno é presente no teu canto, bem-te-vi

(vindo do fundo da via como no passado ouvi)

E logo os outros repetem: bem te vi, te vi, te vi

Como outrora, como agora, como no passado ouvi

(vindo do fundo da vida)

Meu coração diz pra si: as aves que lá gorjeiam não gorjeiam como aqui

\section{Considerações Finais}

(In: GULLAR, 2004)

A negação das impressões imediatas com relação à vocação literária é aqui substituída pelo esforço de compreensão desta atividade a partir da submissão dos agentes às lógicas de funcionamento de uma estrutura de relações sociais específica, tomando-se por objeto de análise o acionamento desta atuação 
literária enquanto estratégia de afirmação social investida por um conjunto de agentes ingressantes na carreira literária entre os anos de 1945 e 1964, identificando os mecanismos de atuação vinculados às posições por eles ocupadas e que orientam, relativamente, suas tomadas de posição no interior do espaço intelectual maranhense. Constatamos que para os descendentes de personagens destacadas no cenário político e intelectual maranhense - atuantes principalmente durante o início do século $\mathrm{XX}$, que, no entanto, enfrentaram uma vigorosa transformação social, em grande parte decorrente dos rearranjos faccionais que deslocaram seus ascendentes das posições politicamente dominantes -, o exercício literário lhes serve ao preenchimento de duas funções principais: a manutenção de um status intelectual apoiado nos usos do capital de notoriedade do grupo familiar e a possibilidade de inserção em redes de relações sociais situadas a meio caminho entre a "vala dos comuns" e os grupos dirigentes. Não sendo a titulação escolar seu principal recurso social acionado, segundo identificamos a partir dos dados coletados utilizando-nos do método prosopográfico ${ }^{8}$, estes tenderam a padrões medianos, com títulos adquiridos em instituições privadas da capital ou com breves passagens por outros estados. Em um contexto de expansão, ainda que lento, do número de cursos em nível superior e da progressiva importância que estes adquirem no processo de consagração intelectual (cf. NUNES, 2002), os agentes destituídos deste recurso têm que se resignar a uma dupla subordinação: suster-se à margem dos grupos dirigentes pela atuação literária e à dependência da política como condição de sobrevivência de suas obras - o que se exemplifica pelo elevado número de publicações financiadas pelo estado - e de si mesmo, já que neles não havia nem disposição nem detinham recursos para a profissionalização fora do serviço público, onde tenderam a ocupar postos pouco relevantes e vinculados à produção cultural. 
Enquanto aqueles se afirmavam, principalmente, através do uso estratégico das associações com os grandes feitos dos seus familiares, com ênfase sobre as características intelectuais dos seus ascendentes, outros, membros de novos grupos sociais em ascensão, tenderam a investir na aquisição de títulos de formação superior diversificados, com maior concentração em Direito, ou mesmo pós-graduando-se na capital e outros estados, todos adquiridos em instituições públicas. Estes casos constituem o perfil dos agentes melhor sucedidos em relação aos postos públicos ocupados, exercendo cargos médios e altos, além de serem os que mais se aproximam do pólo mais dominante do estado, vinculando-se a setores jurídicos e econômicos da sua administração. Porém, no que tange ao reconhecimento literário, não cumpre à titulação escolar o papel preponderante, mas ao nível mais pessoalizado das lógicas sociais em jogo. Neste ponto a inserção em movimentos culturais e os engajamentos políticos faccionais se sobressaem. Os nomes mais consagrados literariamente dentre os 37 agentes que analisamos ombrearam os principais movimentos culturais ocorridos em São Luís nos idos de 1945 a 1964, com maior destaque para os que se inseriram ainda em redes de relações sociais e administraram contatos qualificados em contextos mais centrais do país, como alguns casos que viveram, ou vivem ainda, em Minas Gerais, Rio de Janeiro, Paraná, Bahia, São Paulo ou no exterior, utilizando-se também destas experiências como importantes recursos de afirmação neste espaço.

Apresenta-se assim uma contribuição inicial para a compreensão dos condicionantes sociais e estratégias de afirmação literária no contexto maranhense. As dimensões de análise apontadas neste trabalho nos possibilitam em diante um exame mais acurado das adesões e solidariedades que integram o sistema de relações sociais em que interagem os intelectuais maranhenses, tomando-se esta noção a partir da atuação destes agentes nas imbricações entre os domínios político e literário, permitindo-nos um maior detalhamento das relações intersticiais em que inserem. 


\title{
ANEXO - Lista dos 37 agentes analisados
}

\author{
Antenor Mourão Bogéa \\ Bernardo Coelho de Almeida \\ Clóvis Pereira Ramos \\ Dagmar Destêrro e Silva \\ Durval Cunha Santos \\ Franklin de Oliveira (pseudônimo de José Ribamar de Oliveira Franklin da Costa) \\ Inácio de Mourão Rangel \\ Jamil Jorge (pseudônimo de Jamil Daud Murad Hiluy) \\ João Batista Bastos Coqueiro \\ João Miguel Mohana \\ Jomar da Silva Moraes \\ José Carlos Lago Burnett \\ José de Jesus Louzeiro \\ José do Nascimento Moraes Filho \\ José Francisco das Chagas \\ José Maria Nascimento \\ José Maria Ramos Martins \\ José Pereira Brasil \\ José Ribamar Ferreira Gullar \\ José Sarney (José Ribamar Ferreira de Araújo Costa) \\ José Tribuzi Pinheiro Gomes Bandeira Tribuzi \\ José Vera-Cruz Santana \\ Justo Sebastião Jansen Ferreira \\ Lucy de Jesus Teixeira \\ Magson Gomes da Silva \\ Manuel Alexandre de Santana Sobrinho \\ Maria da Conceição Ferreira \\ Maria da Conceição Neves Aboud \\ Mário Martins Meireles \\ Nauro Diniz Machado \\ Olavo Alexandrino Correia Lima \\ Olímpio Martins da Cruz \\ Osmar Rodrigues Marques \\ Oswaldino Marques \\ Raimundo Nonato Ferro do Lago \\ Tobias de Sousa Pinheiro Filho \\ Venúsia Cardoso Neiva
}




\section{Referências Bibliográficas}

ALMEIDA, Alfredo Wagner Berno de. A Ideologia da Decadência: leitura antropológica a uma história da agricultura no Maranhão. Rio de Janeiro: Editora Casa 8/FUA, 2008.

MARTINS, Manoel Barros. Operários da Saudade: os novos atenienses e a invenção do Maranhão. São Luís: Edufma, 2006.

BADIE, Bertrand \& HERMET, Guy. Las dinámicas huérfanas. In: Política comparada. México: Fondo de Cultura Econômica, 1993.

BOURDIEU, Pierre. Razões práticas: sobre a teoria da ação. Campinas: SP: Papirus, 2005.

. Leitura, leitores, letrados, literatura. In: BOURDIEU, Pierre. Coisas Ditas. São Paulo: Brasiliense, 2004.

As regras da arte: gênese e estrutura do campo literário. São Paulo: Companhia das Letras, 2002.

BOISSEVAIN, Jeremy. Coaliciones. In: SANTOS, Félix Requena. Análisis de redes sociales. Barcelona: Siglo Veintiuno, 2003.

BORRALHO, José Henrique de P. Terra e céu de nostalgia: tradição e identidade em São Luís do Maranhão. São Luís: Café e Lápis, 2011.

CHARLE, Christophe. Situation spatiale et position sociale: essai de géographie sociale du champ littéraire à la fin du 19e siècle. Actes de la Recherche en, Sciences Sociales, année 1977, volume 13, numéro 1, p. 45-59.

CORADINI, O. L. As missões da "cultura» e da "política": confrontos e reconversões de elites culturais e políticas no Rio Grande do Sul (1920-1960). Rio de Janeiro: Revista Estudos Históricos, ${ }^{\circ}$ 32, 2003, p. 125-144.

GRILL, Igor G. Os usos dos "ismos" em batalhas políticas e intelectuais (RS/ MA). $\mathbf{3 4}^{\circ}$ reunião anual da ANPOCS, 2010.

GRILL, Igor e REIS, Eliana T. Letrados e Votados: Lógicas cruzadas do engajamento político no Brasil. In: Revista Tomo, n 13, 2008, p. 127-168.

NASCIMENTO, Dorval do. Nosso céu não tem estrelas: o campo intelectual maranhense na primeira república. Anais do XXVI Simpósio Nacional de História - ANPUH, São Paulo, julho 2011.

NUNES, Patricia Maria Portela. Medicina, poder e produção intelectual: uma análise sociológica da medicina no Maranhão. São Luís: Edições UFMA/PROIN (CS), 2000. 
SAPIRO, Gisèle. Elementos para uma história do processo de autonomização: o exemplo do campo literário francês. Tempo Social, 2004, p. 94-104.

PÉCAUT, Daniel. Os intelectuais e a política no Brasil: entre o povo e a nação. São Paulo: Ática, 1990.

REIS, Eliana T. dos. Juventude, Intelectualidade e Política: espaços de atuação e repertórios de mobilização no MDB gaúcho dos anos 70. Dissertação de Mestrado em Ciência Política, UFRGS, 2001.

. Contestação, Engajamento e Militantismo: da "luta contra a ditadura” à diversificação das modalidades de intervenção política no Rio Grande do Sul. Tese de Doutorado em Ciência Política/UFRGS, 2007.

Referencial e mediação na produção de políticas públicas para a cultura no Maranhão. $3^{\circ}$ Encontro anual da ANPOCS, 2009.

SIGAL, Silvia. Introdução: Intelectuales, cultura y política”. In.: SIGAL, Silvia. Intelectuales y poder em Argentina em la década del sesenta. Argentina: Siglo veintiuno de Argentina Editores, 2002, p. 1-17.

SILVA, Franklin L. A Literatura Como Condição: apontamentos para a análise das entradas na carreira literária no Maranhão contemporâneo (1945-1964). Revista Outros Tempos, V. 8, número 11, 2011 - Dossiê História e Literatura. WACQUANT, LoÏc. Mapear o campo artístico. Sociologia, problemas e práticas, $\mathrm{n}^{\circ} 48,2005$, p. 117-123.

\section{Fontes de pesquisa}

Antologia da AML, 1908-1958. AML: São Luís, 2008.

ALMEIDA, Zafira da Silva de. Gênese da Academia Maranhense de Ciências. São Luís: Editora UEMA, 2009.

BRASIL, Assis. A Poesia Maranhense no Século XX. SIOGE/Imago: São Luís, 1994.

CORRÊA, Rossini. O Modernismo no Maranhão. Corrêa \& Corrêa Editores: Brasília, 1989.

COUTINHO, Milson. A presença do Maranhão na Câmara dos Deputados (1826-2006). Editora Legenda: São Luís, 2007.

CRUZ, Arlete Nogueira da. Nomes e Nuvens. Unigraf: São Luís, 2003. 
DINO, Sálvio. A Faculdade de Direito do Maranhão (1918-1941). EDUFMA: São Luís, 1996.

GULLAR, Ferreira. Toda Poesia. José Olympio Editora: Rio de Janeiro, 2004.

LEÃO, Ricardo. Tradição e ruptura: a lírica moderna de Nauro Machado. Fundação Cultural do Maranhão: São Luís, 2002.

Livro do Centenário da AML (1908-2008). Edições AML: São Luís, 2009.

MACHADO, Nauro. Trindade Dantesca. Unigraf: São Luís, 2008.

MEIRELES, Mário M. O ensino superior no Maranhão. In: MEIRELES, Mário M. Dez estudos históricos (coleção documentos maranhenses). Alumar: São Luís, 1994, p. 45-94.

Apontamentos para a história da Farmácia no Maranhão. UFMA/CAPES: São Luís, 1982.

MOHANA, João. A grande música no Maranhão. SECMA: São Luís, 1995.

MORAES, Jomar. Perfis Acadêmicos. Edições AML, 1993.

Perfis Acadêmicos. Edições AML, 1987.

. Guia de São Luís do Maranhão. s/d.

. Apontamentos de literatura maranhense. SIOGE: São Luís,

MORAIS, Clóvis. Terra timbira. Brasília, 1980.

RAMOS, Clóvis. A intelectualidade maranhense: fase contemporânea. Centro Gráfico do Senado Federal: Brasília, 1990.

Supl. Cult. e Lit. JP Guesa Errante: Anuário: São Luís, n 3, 2005; n 5, 2007; $n^{\circ}$ 6, 2008; $n^{\circ}$ 7, 2009 e edição 221 de 10 de setembro de 2010 .

SILVA, Celeste Amância Aranha e. Jornais maranhenses (1821-1979). Func/ Biblioteca Benedito Leite: São Luís, 1981.

Recebido em 02.03.2013

Aprovado em 23.05.2013 
